\title{
Applying Mechanistic Dam Breach Models to Historic Levee Breaches
}

\author{
Paul Risher ${ }^{1, a}$, and Stanford Gibson ${ }^{2}$ \\ ${ }^{1}$ US Army Corps of Engineers, Risk Management Center, Davis, California, USA \\ ${ }^{2}$ US Army Corps of Engineers, Hydrologic Engineering Center, Davis, California, USA
}

\begin{abstract}
Hurricane Katrina elevated levee risk in the US national consciousness, motivating agencies to assess and improve their levee risk assessment methodology. Accurate computation of the flood flow magnitude and timing associated with a levee breach remains one of the most difficult and uncertain components of levee risk analysis. Contemporary methods are largely empirical and approximate, introducing substantial uncertainty to the damage and life loss models. Levee breach progressions are often extrapolated to the final width and breach formation time based on limited experience with past breaches or using regression equations developed from a limited data base of dam failures. Physically based embankment erosion models could improve levee breach modeling. However, while several mechanistic embankment breach models are available, they were developed for dams. Several aspects of the levee breach problem are distinct, departing from dam breach assumptions. This study applies three embankments models developed for dam breach analysis (DL Breach, HR BREACH, and WinDAM C) to historic levee breaches with observed (or inferred) breach rates, assessing the limitations, and applicability of each model to the levee breach problem.
\end{abstract}

\section{Introduction}

Hurricane Katrina changed the US Army Corps of Engineers' (USACE) approach to infrastructure risk assessment [1]. USACE added life safety risk analysis to classic analyses that focused on economic cost-benefit analysis. Consequence models (e.g. life and safety) use dynamic floodplains results from a hydraulic model to determine the exposure of and impact to a population protected by a dam or levee. Assumptions about the rate and size of a levee breach are expected to impact consequence results by significantly changing the depth and arrival time of flooding to the impacted area. Modeling life and safety risk requires better temporal resolution for dam and levee failure models than classical damage analysis in order to model the impact of warning and evacuation $[2,3]$. It's not just the ultimate depth, but the flood timing and velocity that become important to survival. These rare breach events tend to be rapid, catastrophic, and unexpected, making them difficult to measure. When a levee breaches, data collection is not a high priority, thus scant historical data on breach parameters or progressions is available. Out of necessity, levee breach progression is often defined or parameterized using gross assumptions and limited historic information.

Dam failure analysis encountered similar data limitations for similar reasons. However, experimental research has made some progress on the physics of the breach propagation. This research has been incorporated into several breach models [4]. Since levees are also embankments, these physically based dam models are often suggested for levee breach analysis [3]. Mechanistic dam breach models are rarely applied to levee breach scenarios, however, because the levee breach problem has unique components that make dam breach models difficult to apply directly [5].

Breach model parameters affect the dimensions and rate of the opening. A large rapid breach fills a leveed area quickly, making evacuation more difficult, leading to more modelled life loss. A small, slower breach produces slow rising flood depths and generally delayed flooding, improving evacuation results. Modelled life loss, and presumably, the actual safety risk, can change dramatically based on the levee breach timing and magnitude assumptions, impacting funding decisions and public safety if risk is misrepresented. Modeling the breach correctly or at least knowing the range of possible outcomes limits the error in life loss modelling and improves flood risk management decisions.

This study investigates the applicability of mechanistic dam breach models to levees. Three breach models (WinDAM C, HR BREACH 4.3, and DL Breach) were applied to two historical levee breaches to test their limitations and portability to and compatibility with other

${ }^{\mathrm{a}}$ Corresponding author: paul.b.risher@usace.army.mil 
levee breach applications, e.g. hydraulic and/or consequence models.

\section{Methods}

\subsection{Distinctive Levee Breach Processes}

Dam and levee embankment breaches have many similarities in the physical process, but there are some distinct differences that complicate use of these models for levees [5]. A dam impounds flow, forcing all or most of the flow through the breach. If some of the flow is diverted through gates or spillways, it recombines with breach flow downstream Fig. 1. The tailwater is dynamic and includes all flow. A levee breach splits flow. Part of the flow passes through the breach and into the leveed area while the remainder of the flow continues down the river. Therefore, only part of the flow feeds the levee breach tailwater which tends to be hydrostatic inside the leveed basin. However, this tail water effect tends to be more important for levees than dams.

In both cases the flow through the breach increases as the width grows and then slows after a peak. However, in the dam breach case, flow decreases as the reservoir storage is exhausted and the head behind the dam falls (headwater dominated). Most levee breaches are not supply limited in the same way; the flow in the main channel usually maintains most of the driving head. Instead, levee breach flows tend to slow in response to rising, hydrostatic tailwater (tailwater dominated). Dams are typically much taller than levees making the breach flow more sensitive to deepening than widening while the opposite is true for levees. They usually reach the full breach depth quickly but continue to widen long after.

Another distinction is the direction of inflow and impact of momentum on the breach outflow [5]. While a dam has a basically static headwater, the river approaching a levee breach is typically in flood stage and moving with considerable momentum that is only increased by the sudden breach opening. The angle of approach may also have impact on the breach opening geometry, favoring the downstream edge for erosion [6].

Finally, because dams tend to be perpendicular to flow, a single horizontal water surface elevation can be an effective assumption. Levees tend to run parallel to the dominant flow, introducing a sloping water surface in the region of the breach. However, this difference tends to be less sensitive than those described above.

These distinctions between levee and dam breach processes can complicate applications of dam breach models to levees, requiring several simplifying assumptions that impact the headwater, tailwater, and breach hydraulics.

Preselecting constant headwater and tailwater stages artificially limits breach flow and erosion. Breach progression has important feedbacks with both the headwater and tailwater that need to be captured to properly model the breach growth. Tailwater reduces flows through the breach by the time it approaches about $65 \%$ of the breach flow depth [7]. To account for these distinct processes, dam breach models must incorporate tail water effects, or be coupled with a hydrodynamic model either iteratively or implicitly.

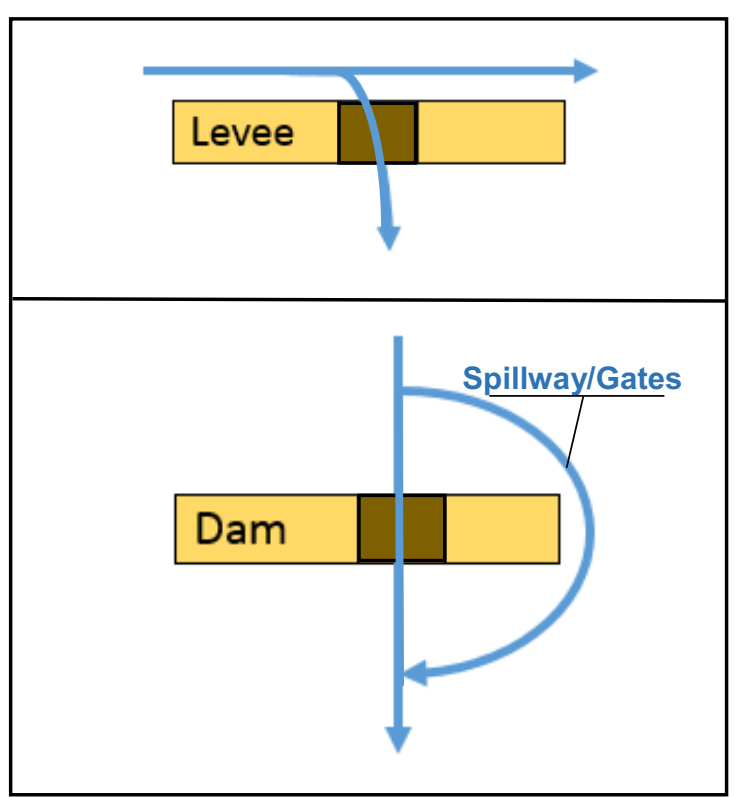

Figure 1. Levee and dam flow paths

\subsection{Breach Models}

This study compared three embankment breach process models: DL Breach, HR BREACH, and WinDAM C. The models have different input parameters, modeled processes (Table 1), and boundary conditions (Table 2) making direct comparisons difficult. Table 2 summarizes the available boundary conditions for each model. Each model represented the historic breaches with hydraulic and geotechnical conditions. For each breach an HECRAS model reproduces historic breach hydrodynamics by modeling the breach opening as observed and measured. HEC-RAS results became hydraulic inputs to the breach models (headwater and tailwater hydrographs). This was necessary because none of the models allows for flow through the headwater as a river does and introduces error by forcing a headwater correctly as described above.

The breach models all allow for breach initiation by overtopping or piping through the embankment. They can all compute erosion of a protective surface layer, head cut development and breach widening. HR BREACH and DL Breach also compute sediment transport and surface erosion for non-cohesive materials. The processes modeled in each software are presented in Table 1.

Generally, each model uses the excess shear stress equation, below, to compute headcut migration and erosion rates $[5,8]$.

$$
\varepsilon_{R}=k_{d}\left(\tau-\tau_{c}\right)^{n}
$$


Where $\varepsilon_{R}$ is the erosion rate, $k_{d}$ is the erodibility coefficient, $\tau$ is the hydraulic shear stress, and $\tau_{\mathrm{c}}$ is the critical shear stress, and the non-linear calibration parameter, $\mathrm{n}$, is assumed to be 1 (linear).

The exception is for non-cohesive erosion which is calculated by various sediment transport equations in DL Breach and HR BREACH. These models each have detailed documentation which provides description of the parameters and governing processes. The overview of each model below focuses on important distinctions for this study.

Table 1: Modeled Processes

\begin{tabular}{|l|c|c|c|}
\hline Process & WinDAM & $\begin{array}{c}\text { DL } \\
\text { Breach }\end{array}$ & $\begin{array}{c}\text { HR } \\
\text { BREACH }\end{array}$ \\
\hline River Hydraulics & No & N & N \\
\hline Breach Flow & Yes & Y & Y \\
\hline $\begin{array}{l}\text { Internal Hydraulic } \\
\text { Routing }\end{array}$ & N & N & Y \\
\hline $\begin{array}{l}\text { Tailwater } \\
\text { Submergence }\end{array}$ & $\mathrm{Y}$ & $\mathrm{Y}$ \\
\hline Piping Initiated & $\mathrm{Y}$ & $\mathrm{Y}$ & $\mathrm{Y}$ \\
\hline $\begin{array}{l}\text { Overtopping } \\
\text { Initiated }\end{array}$ & $\mathrm{Y}$ & $\mathrm{Y}$ & $\mathrm{Y}$ \\
\hline $\begin{array}{l}\text { River Erosion and } \\
\text { Stability Failure } \\
\text { Initiated }\end{array}$ & $\mathrm{N}$ & $\mathrm{N}$ & $\mathrm{N}$ \\
\hline Headcut & $\mathrm{Y}$ & $\mathrm{Y}$ & $\mathrm{Y}$ \\
\hline Breach Widening & $\mathrm{Y}$ & $\mathrm{Y}$ & $\mathrm{Y}$ \\
\hline Breach Deepening & $\mathrm{Y}$ & $\mathrm{Y}$ & $\mathrm{Y}$ \\
\hline $\begin{array}{l}\text { Foundation } \\
\text { Scouring }\end{array}$ & $\mathrm{N}$ & $\mathrm{Y}$ & $\mathrm{N}$ \\
\hline $\begin{array}{l}\text { Mass Wasting } \\
\text { (geotechnical } \\
\text { failure) }\end{array}$ & $\mathrm{Y}$ & $\mathrm{Y}$ & $\mathrm{Y}$ \\
\hline $\begin{array}{l}\text { Surface Erosion } \\
\text { by Sediment } \\
\text { Transport }\end{array}$ & $\mathrm{N}$ & $\mathrm{Y}$ & $\mathrm{Y}$ \\
\hline Sediment Volume & $\mathrm{N}$ & $\mathrm{Y}$ & $\mathrm{Y}$ \\
\hline $\begin{array}{l}\text { Surface Protection } \\
\text { Removal }\end{array}$ & $\mathrm{Y}$ & $\mathrm{Y}$ \\
\hline $\begin{array}{l}\text { Composite } \\
\text { Material Zones }\end{array}$ & $\mathrm{Y}$ & \\
\hline
\end{tabular}

The initiation mechanism is important to establish the time of breach formation. Overtopping or piping may persist for hours to months before the levee is breached. Overtopping can be greatly impacted by the presence of a surface protection element such as riprap or turf grass. Two of the models can calculate removal of the surface protection, although that functionality was not tested in this study. It is assumed to work the same for dams or levees.

While headcut migration and piping are important to formation time, they do not have a large impact on the peak breach hydrograph. The leveed area water depth, velocity and volume are more a function of breach growth rate and differential head, and are the focus of this investigation.

\subsubsection{Breach}

DL Breach (2015) was developed by Dr. Weiming Wu $[9,10]$. It computes a surface erosion rate with a transport equation for cohesionless soils or an excess shear equation (for cohesives) with the option of simulating headcut progression. DL Breach also allows users to define more complex geometries considering, including an embankment core or cover with distinct soil properties. DL Breach computes a different breach geometry than the other two headcut models (Fig. 2), it computes two breach widths: one on the downcutting flat crest and the other on the backward eroding downstream slope. This study used the width of the flat top breach because it controls the flow rate. Visser has demonstrated the non-cohesive geometry using beach sand [11], while Zhu has it for cohesive breaches [12].

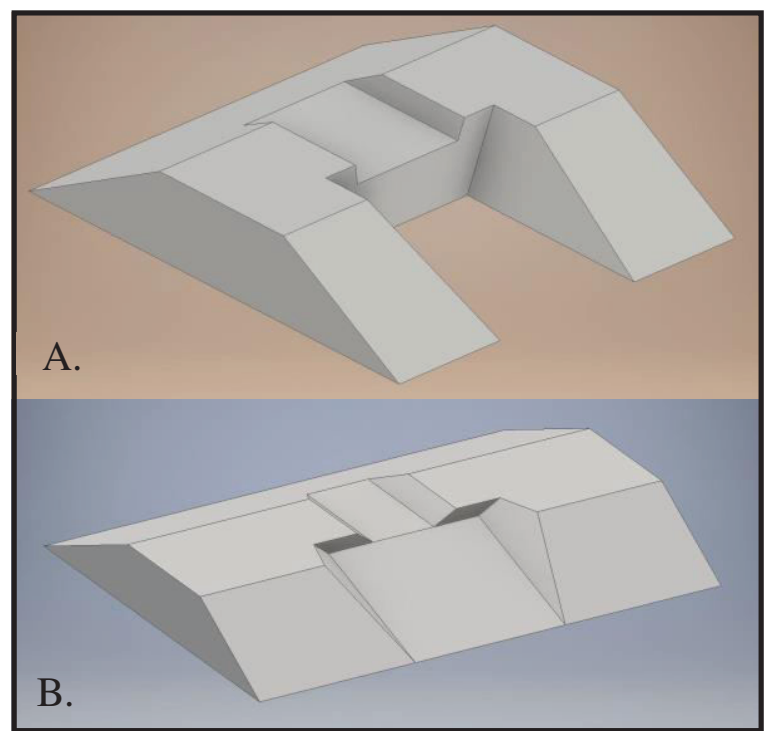

Figure 2. 3D view of breach progression for cohesive soil with headcut (A) and cohesionless soil (B). [9]

Other geometry differences include the ability to add scour below the bottom of the levee and a unique breach widening routine. It is the only model that has a scour option and it was used in both breach cases. The widening routine calculates lateral erosion for each timestep which steepens the side slope until there is a geotechnical stability failure and reestablishes a stable slope geometry.

DL Breach does not calculate hydraulics through the breach but determines breach flow by, weir, orifice or normal depth equation depending on the location. It saves considerably on run time, but is likely introducing error to the outflow hydrograph especially when the breach has reached full depth or scoured and only widening. Applying the weir equation to this case is beyond its intention.

The options for boundary conditions limit applications. In DL Breach headwater is assumed to be a reservoir or a stage hydrograph requiring a coupled or iterative hydraulic model to define it. Tailwater can only be a reservoir which unfortunately did not approximate 
conditions well due to secondary breaches that returned water to the river.

\subsubsection{HR BREACH}

HR BREACH v4.3 was developed at HR Wallingford by Mohamed Hassan and Mark Morris [13]. It evolved into EMBREA and AREBA that expand its original capability to more complex geometries and faster computation times, respectively along with other improvements. This analysis was conducted with HR BREACH version 4.3, which simulates overtopping or piping breaches with a user selected erosion method. Methods include several sediment transport equations and the excess shear equation mentioned above. The excess shear method was selected because it is preferred by the developers and makes the best comparison to the other models. HR BREACH also has a headcutting option, but it uses the Hanson/Robinson Energy method [14]. The stress method is recommended by Hanson as being more accurate. One of the problems with the Energy method is that it relies on a coefficient of headcut migration, $\mathrm{C}$, that has little background information. Hanson recommends an approximation of $0.5 \mathrm{k}_{\mathrm{d}}$, which adds to the model uncertainty.

HR BREACH requires several more geotechnical parameters than the other two models, however not all parameters are used for every erosion method.

Full 1D hydraulic calculations are a unique feature of HR BREACH. The breach flowpath is broken into several cross sections and the location of hydraulic control calculated for every timestep, allowing it to move as erosion progresses. This allows for more detailed calculations of hydraulic shear stress and sediment transport. Bed erosion is calculated and applied with a factor of 1.5 as the widening rate which updates the breach geometry. Geotechnical failure limits are also checked and if triggered, add to the transported sediment volume and updates the geometry.

The program can route a hydrograph through the reservoir using gates and spillways, and allows for several downstream boundary conditions making it the most versatile for boundary conditions.

\subsubsection{WinDAM C}

WinDAM C is the latest version of the US Department of Agriculture - Agricultural Research Station (USDAARS) breach software and still a beta version. Originally called SIMBA, it was developed to replicate headcut erosion tests by Temple and Hanson as an extension of the former SITES software [8, 14, 15]. Version C simulates breach initiation by overtopping or piping in cohesive soils [16]. It also calculates surface protection loss with a shear stress limit for grass, riprap or bare earth materials. The program assumes headcutting dominates the breach mechanism, which is most appropriate for cohesive soils, but may limit the applicability of WinDAM C for sandy, or cohesionless soils. WinDAM
$\mathrm{C}$ also utilizes a headcut on the downstream end of the piping conduit if it forms above the base of the dam.

No internal breach hydraulics are calculated, instead flow is given by a weir or orifice equation. Flow and erosion rates are reduced for tailwater submergence.

The headwater is assumed to always have a reservoir and inflow hydrograph. Several gates and spillways are available and tailwater must be represented with a rating curve.

Table 2. Allowable Hydraulic Boundary Conditions

\begin{tabular}{|l|c|c|c|}
\hline \multicolumn{1}{|c|}{ Type } & WinDAM & $\begin{array}{c}\text { DL } \\
\text { Breach }\end{array}$ & $\begin{array}{c}\text { HR } \\
\text { BREACH }\end{array}$ \\
\hline $\begin{array}{l}\text { US Inflow } \\
\text { Hydrograph }\end{array}$ & $\mathrm{Y}$ & $\mathrm{Y}$ & $\mathrm{Y}$ \\
\hline US Reservoir & $\mathrm{Y}$ & $\mathrm{Y}$ & $\mathrm{Y}$ \\
\hline $\begin{array}{l}\text { US Stage } \\
\text { Hydrograph }\end{array}$ & $\mathrm{N}$ & $\mathrm{Y}$ & $\mathrm{Y}$ \\
\hline $\begin{array}{l}\text { US Channel } \\
\text { Profile (Sloped } \\
\text { Water Surface) }\end{array}$ & $\mathrm{N}$ & $\mathrm{N}$ & $\mathrm{N}$ \\
\hline $\begin{array}{l}\text { Spillway/Gate } \\
\text { Outflow }\end{array}$ & $\mathrm{Y}$ & $\mathrm{Y}$ & $\mathrm{Y}$ \\
\hline $\begin{array}{l}\text { DS Rating } \\
\text { Curve }\end{array}$ & $\mathrm{Y}$ & $\mathrm{N}$ & $\mathrm{Y}$ \\
\hline DS Reservoir & $\mathrm{N}$ & $\mathrm{Y}$ & $\mathrm{Y}$ \\
\hline $\begin{array}{l}\text { DS Stage } \\
\text { Hydrograph }\end{array}$ & $\mathrm{N}$ & $\mathrm{N}$ & $\mathrm{Y}$ \\
\hline $\begin{array}{l}\text { DS Normal } \\
\text { Depth Channel }\end{array}$ & $\mathrm{N}$ & $\mathrm{Y}$ & $\mathrm{Y}$ \\
\hline \begin{tabular}{l} 
US Upstream, DS: Dow \\
\hline
\end{tabular} & & \\
\hline
\end{tabular}

US: Upstream, DS: Downstream

\subsubsection{Hydraulic Boundary Conditions}

Appropriately modeling headwater and tailwater emerged as one of the biggest challenges to applying these models in levee breaching scenarios. Each model handled the conditions differently requiring unique simplifying assumptions.

Because the models assume a dam configuration, they cannot accommodate a dynamic headwater with river flow bypassing the breach site. Using the HEC-RAS headwater from the historic breach simulation may skew the results because it includes the impact of the historical breach. If the modeled breach is larger than historical it should draw down the headwater, but instead is subjected to higher levels which artificially accelerates the breach. Conversely if the modeled breach is smaller, the headwater should stay elevated for longer allowing faster modeled breach growth. Instead the HEC-RAS results drop the headwater in relation to the historic breach opening and exacerbate the slow modeled breach growth. Each case represents a positive feedback toward a more wrong answer with unknown error magnitude.

WinDAM C is able to dynamically update the headwater with some simplifying assumptions. First a control volume $(\mathrm{CV})$ near the breach is isolated and represented 
by the "reservoir" with a stage-volume table. Second the "auxiliary spillway" is given a rating curve from the outflow of the river $\mathrm{CV}$, e.g. the downstream cross section. Third, a hydrograph is given for river flow into the CV. Then WinDAM updates the stage dynamically for each timestep improving headwater and breach flow interaction.

One side effect is that this invalidates the tailwater assumption because flows are recombined instead of split. Tailwater could not be represented correctly by the rating curve option anyway, so a hydrostatic tailwater override was used at a single elevation for the whole simulation. The elevation was chosen as roughly the long term tailwater stage in HEC-RAS so that when head is high it does not have much impact, but as the breach opens and headwater drops, the tailwater starts to impact flow rate.

HR BREACH allows a tailwater time series, which made it effective for the forensic analysis in this study but which makes it difficult to apply if those conditions are not known a priori. Similar to the headwater feedback described above, using the tailwater described in HECRAS can bias the modeled breach. If the breach is opening slower than observed it should have a lower tailwater that keeps driving head high, but using the HEC-RAS tailwater will keep it artificially high and further slow the breach rate. The opposite is true for a faster than observed breach. Tailwater should be high to slow it down but it is held low by the HEC-RAS results. Each situation drives the modeled breach toward more error.

DL Breach does allow a stage-storage relationship that can fill with time, but this feature is under development [17] and could not be applied in this study. Therefore DL Breach is only used without tailwater. After the analysis was complete, DL Breach was updated with more functionality for tailwater, two-way flow, wave loading, and other options.

While these assumptions are usually appropriate for dam breach analysis, these boundary conditions limit the applicability of the models to predict levee breach growth unless modelers run them iteratively with a hydraulic model.

\subsubsection{Other Model Differences}

Sometimes levee breaches form scour holes that dig below the original base of the levee. HR BREACH and WinDAM both limit scour to the base of the levee. Only DL Breach can model foundation scour; however it assumes critical depth for all flows which may not be valid for deep scour conditions [17]. The most recent model version examines this assumption but was not used here.

All three models include surface protection algorithms that take advantage of extensive laboratory work on vegetated and erosion protected slopes. Overtopping flow must remove surface materials (e.g. grass, rip rap, etc.) before it can erode the embankment. This is part of the breach initiation time [18] which can be very important to evacuation and consequence modeling. The piping case is more difficult because initiating conditions that may develop quickly or over years are not fully modeled. Each breach model begins simulation with an open piping conduit. This assumption makes the models less useful for initiation timing than the overtopping case because it assumes erosion has already progressed to an open conduit.

\subsection{Historic Levee Breaches}

The three models each simulated two historic levee breaches with observed breach progressions and available geotechnical and hydrologic data. The two breaches are the 1997 Sutter Bypass breach and the 2011 breach on the Missouri River at Hamburg, IA. Both of these breaches were piping or seepage failures.

\subsubsection{Sutter Bypass 1997, near Meridian, California}

Rain-on-snow events in the Sierra Nevada caused record flows throughout the California Central Valley in January 1997. High flows on the Sacramento River activated overflow weirs, diverting water into the Sutter Bypass channel. Shortly after the peak flow passed on January 4, 1997, the southwest levee failed suddenly, inundating Reclamation District 1660 (RD 1660) and RD 70. No problems or seepage were noted at $5: 00 \mathrm{pm}$, but the breach was observed and reported by $6: 30 \mathrm{pm}$ [19]. The breach grew rapidly, reaching $30-\mathrm{m}$ in an hour and $150-\mathrm{m}$ by 1:00 am [20]. Aerial photos the next morning show a breach just over $200 \mathrm{~m}$ wide and still growing [21], see Fig. 3. The levee was a few meters from overtopping at the time of breach, indicating the failure was internal. The following day, RD 1660 cut the levee crest at the lowest point in the basin allowing it to overtop back into the bypass. This engineered relief breach eventually grew into a full breach and was added to HEC-RAS to compute tailwater effects more precisely, see timing in in Fig. 4. On the evening of 6 January large stone was dumped on both sides of the levee breach to prevent further erosion [19]. 


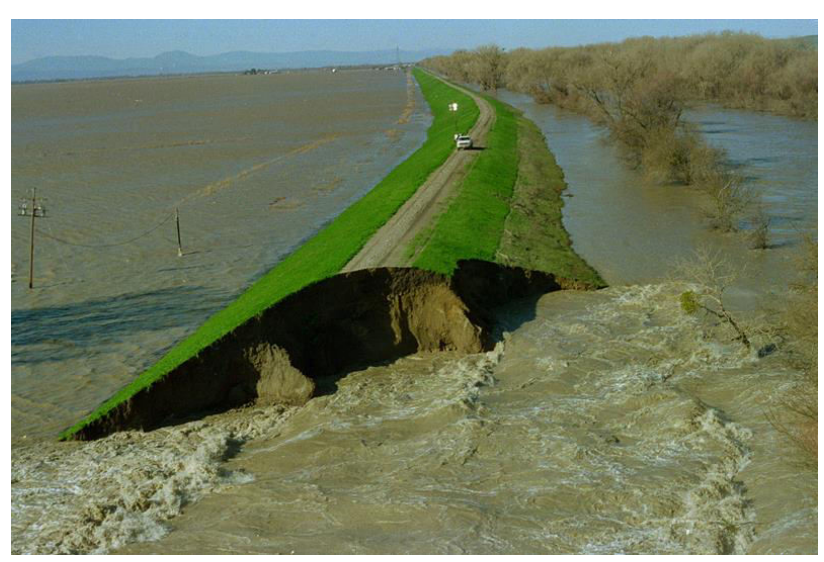

Figure 3: Photo of Sutter Bypass Breach [21]

The levee was built from dredge spoils in the early 1900s. It was placed wet of optimum and received little compaction. In 1940 the basin flooded causing extensive erosion damage to the landside of the levee. The levee was raised and landside repaired using borrow material from the Sutter Bypass. The repair material was collected from the upper two meters of the borrow location instead of the deeper materials used in the rest of the levee. The surface material is mostly clay while deeper materials include more silt and sand. This likely left the original levee more pervious than the repair. In 1955 and 1958 boils, ground heaving, and excessive seepage were observed nearby prompting more than $3 \mathrm{~km}$ of repairs. The breach site was just upstream of the 1958 repair work.

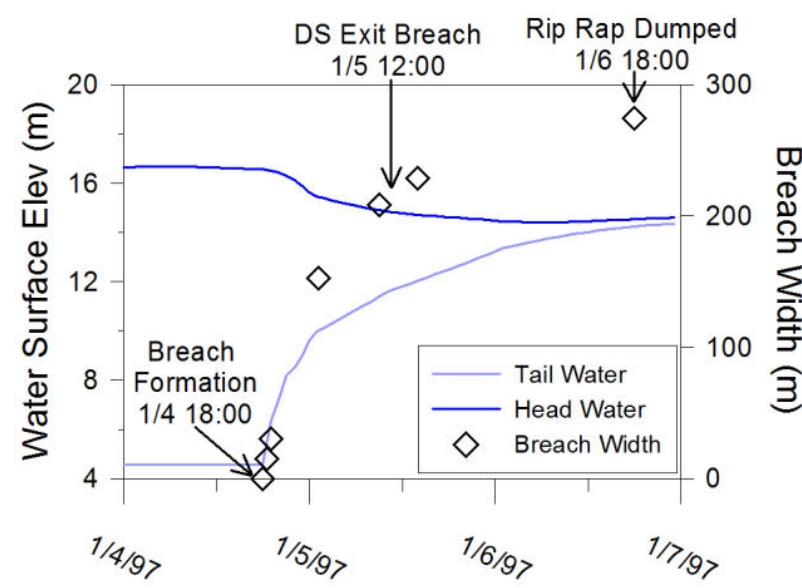

Figure 4: Sutter Bypass Breach Progression and Stages

The precise failure mode is unknown, however the levee did not overtop, indicating some type of seepage failure. Two failure theories emerged. First, a highly permeable sandy layer in the foundation transmitted elevated water pressures to the landside and caused cracking and/or heaving of the hardpan and surficial clay layers similar to the conditions in 1955/58 just downstream. Water began to exit the foundation through cracks triggering erosion of the sandy material that accelerated as the piping conduit enlarged. The levee above settled into a collapsing pipe until the levee crest fell below the water level in the Bypass. Then erosive flows attacked the levee from above and below rapidly expanding the breach width and depth. The second theory is that the levee contained a highly permeable layer from the original construction where it used material excavated from deeper in the canal. The 1941 repair raised the levee and covered the crest and downstream slope with impermeable clay. Seepage in the permeable layer exerted pressure on the confining clay on the surface of the levee causing it to crack. The levee did not show signs of seepage until it failed catastrophically. Flow immediately accelerated through the levee, eroding internal material until the crest settled or collapsed and the breach continued as described above. Both descriptions fit with known conditions and observations of breach timing.

\subsubsection{Missouri River 2011, near Hamburg, lowa}

In the spring and summer of 2011 the Missouri River saw record flows and lengthy flood stages. On the levee near Hamburg, Iowa this led to a series of piping collapses $[22,23]$, ultimately reducing the levee crest to river level and forming a breach 230-m wide (Fig. 5 \& 6). Historic underseepage had been addressed with a seepage berm. However, during high water, piping created foundation voids which collapsed on four occasions, possibly exacerbated by erosion at the waterside levee toe that allowed access to a deeper permeable foundation layer. After four minor collapses, the crest settled below the river water level and breached on 13 June 2011.

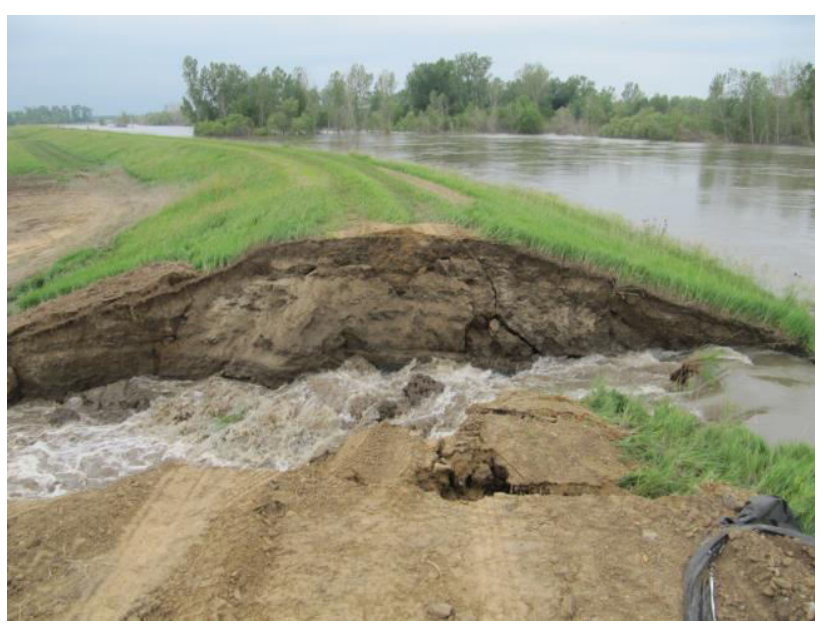

Figure 5: Hamburg Breach 6/13/2011, 9:30am (USACE)

The breach grew rapidly in the first several hours, then widened more slowly but at a relatively constant rate for several weeks. Flow filled the basin and pooled against the southern levee until another breach formed at the lowest point, allowing flow to continue through the breach and basin. This exit breach dropped the tailwater by about a meter, saving the town of Hamburg from flooding, but preserving a head differential at the original breach as flow moved through the basin. Later, on 30 June a third breach opened in the northern end of the basin which started to raise the tailwater again. The third breach was not modeled in HEC-RAS, so results are not discussed beyond that point even though breach widening continued. 


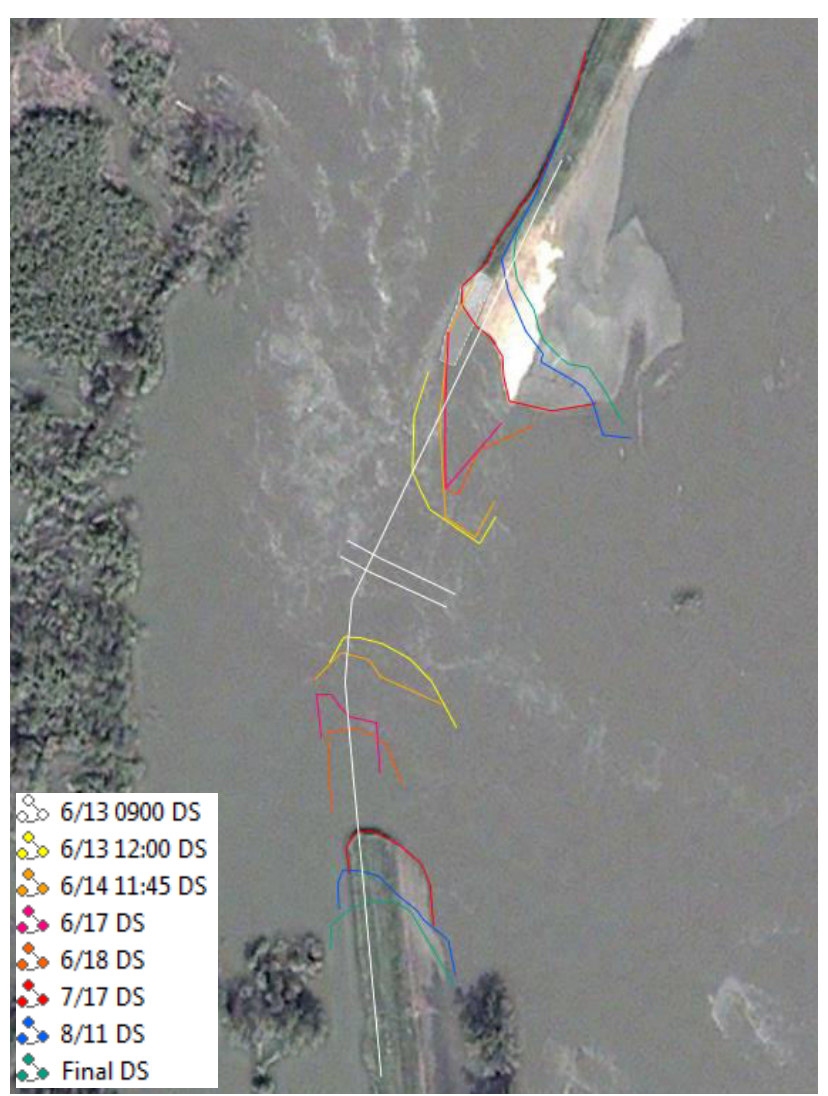

Figure 6: Hamburg Breach Widening (Google Earth)

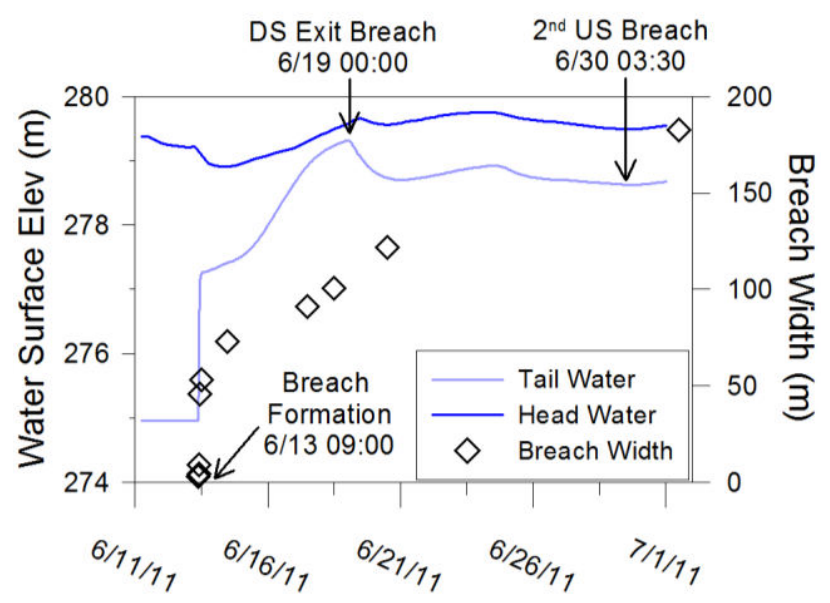

Figure 7: Hamburg Levee Breach Progression and Stages

The Hamburg levee, known as L-575, was built in 1946 as an agricultural levee set back from a shorter, preexisting levee. It used materials from three sources without documentation to describe their placement location. The three sources were: the original dismantled levee, borrow pits in the floodplain, and material dredged from the Missouri River. The dredged material favored coarser grained soils, while finer grained silts and clays were identified in borings of the borrow areas. The original levee was mostly sand with silt and a small fraction of clay. Construction practice did not include significant compaction. Plans indicate either "semicompacted fill" or "hydraulic fill" by dredged material. Photos of the levee interior during breach show horizontal layering and no apparent change in material on the riverside. This indicates the levee was built in a series of lifts as opposed to using confinement levees with dredged hydraulic fill and a clay cap. Underseepage was expected to be a problem so a seepage berm and pressure relief wells were installed on the landside.

Video of the breach shows no headcutting process. The initiation by piping released some nuisance flow until the crest settled below the river level. Then it began to erode rapidly along the entire flow path. As the sides of the breach were undercut they slumped in large pieces into the enlarging breach. The sides appeared to fail by rotation at the bottom of the mass instead of overturning. This failure mechanism, together with evidence of little clay in the borrow material, indicates a predominance of sand and silt with little cohesion in the material.

\subsection{Modeling Process}

In addition to the three breach models an HEC-RAS model was built of each breach. The river was modeled as a 1D reach, the levee as a lateral structure, and the area behind the levee as a storage area with $2 \mathrm{D}$ flow for the Hamburg basin. The hydraulic model computed boundary conditions for the physical breach models, improving headwater and tailwater stage assumptions. The best breach estimate requires accurate approximations of headwater and tailwater stages, matching the hydraulic conditions of the breach as closely as possible.

Applying breach models and hydrodynamic models independently estimates interaction between the developing breach and headwater, tailwater or both. However, modeling feedbacks between the breach and hydraulics more carefully requires a complicated, iterative workflow, passing results manually between the breach model and the hydraulic model. In this study, the HEC-RAS model was not updated based on levee breach results.

Once the model is built the most sensitive and least certain parameters (calibration parameters) were adjusted to approximate the breach width observations (calibration metric). Levee breach rates are highly sensitive to soil properties (e.g. critical shear and erodibility), which vary by orders of magnitude. Since these models were built based on simple soil classification information, instead of measured soil parameters, the critical shear and erodibility, were highly sensitive and highly uncertain, and were selected as calibration parameters

Breach width observations were the primary calibration and model evaluation metric. The breach widening rates exhibited two distinct phases. First, during the "breach formation phase" the breach flow increased and the breach expanded rapidly. Then the breach widening rate slowed and breach flow leveled off or even decreased. This second phase was typically dominated by tailwater. While there were not enough stage or breach flow data to make these a calibration metric, river stages and flooded area water elevations were checked against observations whenever possible to test the consistency of the calibration. 
Because the three breach models use different tailwater assumptions, they were first evaluated against the initial several hours of the breach progression, before tailwater starts to impact breach flow. After the breach models approximated the widening rate, the tailwater was added to the model to reduce the widening rate and match the latter part of the breach progression curve. Tailwater was added either by a single elevation (WinDAM), or by applying the tailwater computed in HEC-RAS (HR BREACH). Specifying the HEC-RAS tailwater did not allow for dynamic update between the tailwater and breach flow and may force the breach model toward the known solution. DL Breach was not able to simulate tailwater adequately in the version tested because it only allowed a stage-area relationship for tailwater, but has since been updated to allow more tailwater options and two-way flow.

Using the available geotechnical information on each levee and typical index properties, a range of possible soil types was developed for each breach. Calibrated parameters were limited to this range from most erodible to least erodible. Material properties were developed as a set in each case so that together they define a realistic soil and to minimize equifinality issues. Cohesive soil models were mostly insensitive to cohesion so erodibility and critical shear were identified as the calibration parameters. The sediment $\mathrm{D}_{50}$ was used for the noncohesive models that calculated surface erosion.

\subsection{Evaluation Data: Observed Levee Breaches}

Table 3. Calibration Parameters for Sutter Bypass

\begin{tabular}{|c|c|c|c|}
\hline & DL Breach & $\begin{array}{c}\text { HR } \\
\text { BREACH }\end{array}$ & WinDAM \\
\hline $\mathrm{k}_{\mathrm{d}}\left(\mathrm{cm}^{3} / \mathrm{N} / \mathrm{s}\right)$ & 20 & 19.4 & $35.4 / 44.2$ \\
\hline$\tau_{\mathrm{c}}(\mathrm{Pa})$ & 0.01 & 0.048 & $0.0048 / 0.024$ \\
\hline $\mathrm{D}_{50}(\mathrm{~mm})$ & 0.1 & 0.1 & NA \\
\hline
\end{tabular}

Table 4. Calibration Parameters for Hamburg

\begin{tabular}{|c|c|c|c|}
\hline & $\begin{array}{c}\text { DL } \\
\text { Breach }\end{array}$ & $\begin{array}{c}\text { HR } \\
\text { BREACH }\end{array}$ & WinDAM \\
\hline $\mathrm{k}_{\mathrm{d}}\left(\mathrm{cm}^{3} / \mathrm{N} / \mathrm{s}\right)$ & $\mathrm{NA}$ & $17.7 / 1.41$ & 44.2 \\
\hline$\tau_{\mathrm{c}}(\mathrm{Pa})$ & 0.1 & $0.048 / 0.24$ & 0.048 \\
\hline $\mathrm{D}_{50}(\mathrm{~mm})$ & 0.5 & 0.3 & $\mathrm{NA}$ \\
\hline
\end{tabular}

\section{Results}

\subsection{Sutter Bypass Breach Results}

Each breaching model reproduced the Sutter Bypass breach width relatively well during the first few hours of rapid breach growth (Fig 8, middle) when calibrated with independent soil parameters (Table 3 ). Calibration varied the erodibility coefficient $\left(\mathrm{k}_{\mathrm{d}}\right)$ and adjusted $\tau_{\mathrm{c}}$ based on assumed relationships between $\mathrm{k}_{\mathrm{d}}$ and $\tau_{\mathrm{c}}[24,25]$. The $\mathrm{k}_{\mathrm{d}}$ and $t_{c}$ were within the expected range, but on the most erodible end in order to replicate the rapid initial opening.

Introducing tailwater could make the models diverge because they represent tailwater differently. However, both HR BREACH and WinDAM C performed very well when tailwater was included. Tailwater was important during the Sutter Bypass breach because the breach progression slowed after about 6 hours. The WinDAM simulation used a constant tailwater of $14.3 \mathrm{~m}$ and some minor adjustments to the soil parameters (Table 3) while HR BREACH used the tailwater time series computed by HEC-RAS. The HEC-RAS tailwater may underestimate tailwater depth at the breach site because it used a storage area - volume relationship instead of 2D hydraulics. This approach neglects road embankments near the levee, which pooled water near the breach before it filled the entire flooded area, introducing tailwater effects sooner than a simple storage area approach would compute. According to the HEC-RAS results, the relief breach in the lower basin did not lower the final tailwater elevation as it approached the headwater elevation, but may have slowed the rate at which the tailwater raised. Despite these limitations both HR BREACH and WinDAM reproduced historic widening rates well. The models performed well in both initial and breach widening phases with calibration parameters developed in the formation phase. 


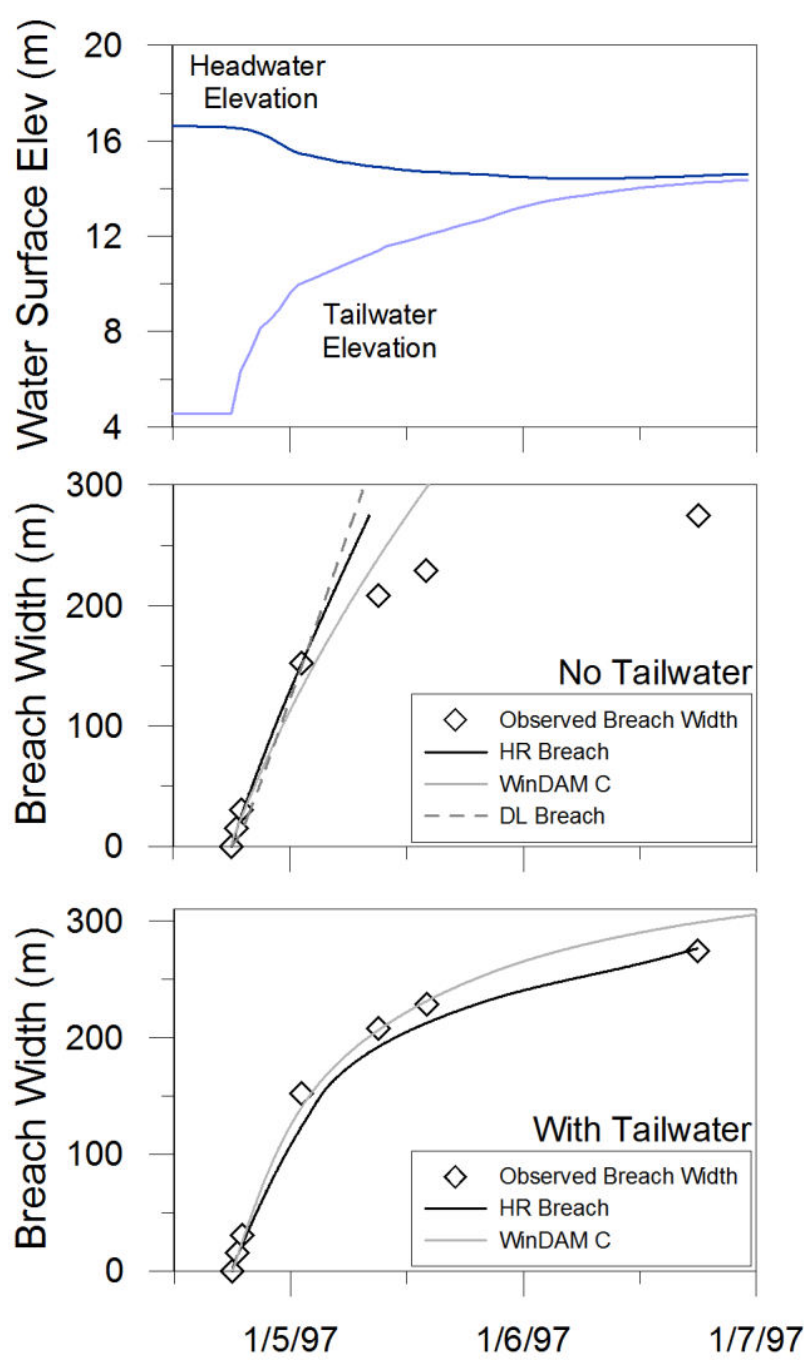

Figure 8 Sutter Bypass breach modeling results. Results include (top) the computed headwater and tailwater from HEC-

RAS, (middle) the widening results from the three models without tailwater, plotted with actual breach widening observations, and (bottom) HR BREACH and WinDAM C, breach widening results, with the observed breach widths.

\subsection{Hamburg Breach Results}

During the Hamburg breach, the HEC-RAS model indicates that the tailwater influences widening rate within a few hours of the breach. All three models were calibrated to $55 \mathrm{~m}$ breach that formed before tailwater slowed the widening rate (Figure 9 middle). Reasonable soil parameters (Table 4) produced good results in all three models though again at the erodible end of the range. In both cases WinDAM required more erodible soils (higher $\mathrm{k}_{\mathrm{d}}$, lower $\tau_{\mathrm{c}}$ ) to calibrate, but all parameters were well within the range of reasonable properties. DL Breach used the non-cohesive erosion routine for the Hamburg breach that does not include $\mathrm{k}_{\mathrm{d}}$, so $\mathrm{D}_{50}$ was used as the calibration parameter.

The full two week breach was modeled again in HR BREACH with the HEC-RAS tailwater time series and in WinDAM with a constant tailwater of $278.9 \mathrm{~m}$, which approximated the final water surface elevation inside the basin. Tailwater effects caused both models to widen more gradually during the beach formation stage.
Predicting more gradual breach formations in those first few hours could under predict flood risk (e.g. over predict evacuation time).
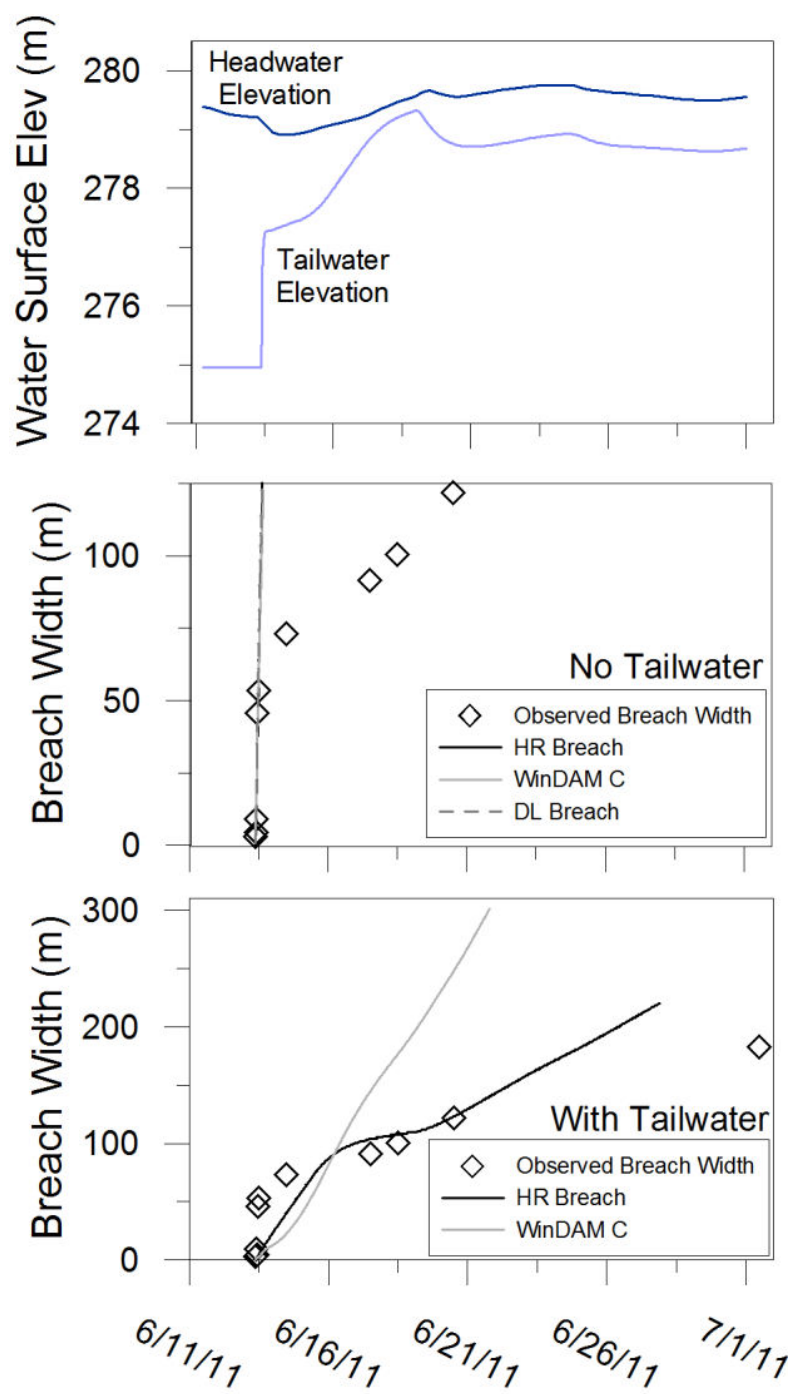

Figure 9: Hamburg breach modeling results. Results include (top) the computed headwater and tailwater from HEC-RAS, (middle) the widening results from the three models without tailwater plotted with actual breach widening observations, and (bottom) HR BREACH and WinDAM C, breach widening results, with the observed breach widths.

However, HR BREACH simulated the week after the breach formation stage very well, computing the observed width on June 21 precisely. After that first week, HR BREACH over-predicting the final width by about $25 \%$, but risk models would not be very sensitive to these differences. WinDAM C's constant tailwater, on the other hand, predicted levee widening rates over the first week that continue at roughly the same rate as the breach formation stage, diverging from the observations. While a constant tailwater performed relatively well on the Sutter Bypass breach, the more complicated, faster developing Hamburg Breach, required more tailwater feedback to model the process. Constant tail water stage models would have to be used iteratively with the hydraulic model to achieve reasonable results. Even breach models with variable downstream stage could 
benefit from iterating results between the breach and hydraulic model.

\section{Discussion}

All three models performed well during the breach formation stage, when calibrated independently. However, the models are extremely sensitive to these soil parameters (e.g. $k_{d}$ and $t_{c}$ ) and while all calibrated parameters fell within the reasonable range for the specified soil type, applying these physically-based models precisely depends on estimating empirical soil parameters more accurately than they can often be determined.

Tailwater effects can also be critical when applying these models originally developed for dam breach scenarios to levee breaches. In some cases, like the relatively simple, slow forming Sutter Breach, simplified tailwater assumptions are sufficient. However, for the more complicated, faster developing breach at Hamburg, a dynamic tailwater is compulsory to approximate the breach progression. Secondary breaches often complicate tailwater hydraulics beyond just filling a basin. Iterative modeling (or an implicit connection between the hydraulic model and breach model) might be required to model both the breach formation phase and the tailwater affected process with the precision required by breach models.

Recent research and model development focused on overtopping breaches initiated by headcutting. Headcutting is typically associated with cohesive materials that can hold a nearly vertical face as erosion continues at the base of the overfall. The figure below from the HR BREACH manual [13] shows the range of headcutting by average grain size, $\mathrm{D}_{50}$. The interaction of a mixture of grain sizes and apparent cohesion may extend this trend to larger $D_{50}$ as their internal strength increases.

WinDAM assumes a headcut develops even during piping breaches while the other models allow for surface erosion more typical of cohesionless materials. This gives them an advantage in flexibility, but it isn't clear how many levees contain materials that would be subject to surface erosion instead of headcutting, although it is more likely than for dams. WinDAM may extend its applicability by assuming no undrained shear strength (non-cohesive) resulting in very short headcutting.

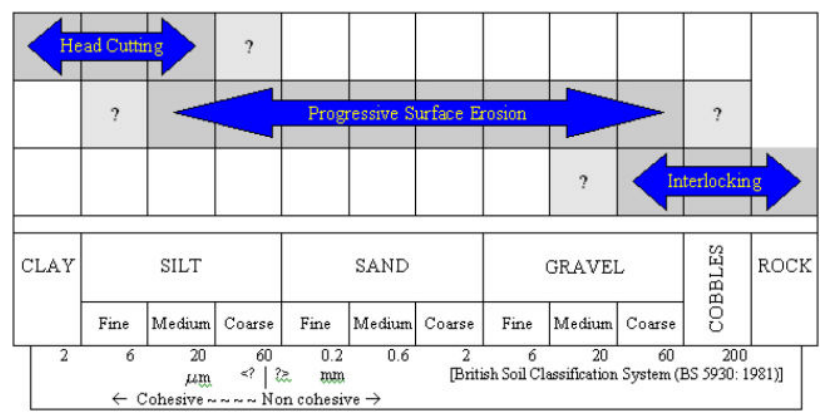

Figure 10: Applicability of Headcut Mechanism [13]
Set up time for each model was about the same once input values were available. HR BREACH and WinDAM both have a graphical user interface to aid the user in parameter selection and provide extensive but not comprehensive background information. DL Breach relies on a text file for input. A recent upgrade (2016) makes the input format object oriented instead of position oriented. Setup time also needs to account for time needed to develop input parameters. WinDAM has fewer parameters, so it took less time to estimate them. Finding data and estimating parameters took much longer than entering these parameters into any of the models. Part of the difficulty is estimating uncertain, highly sensitive parameters from minimal data. Appropriate care should be taken selecting defendable parameters especially considering "physically based methods can be highly sensitive to the assumptions of the analyst." [18].

For both levee breaches, the models would fit the actual breach formation better if the user could specify more erodible soil parameters for the breach formation phase than the tailwater affected phase. Tailwater effects did not seem sufficient to explain the lower breach formation rate by themselves. The modeling suggested that the soil parameters were temporally variable. This temporal variability of soil parameters could be actual (e.g. real or measurable change in soil parameters with time) or apparent (e.g. a numerical artifact of a systemic bias in model assumptions or as a surrogate for another process). Four hypotheses emerged:

1. Loss of Confining Pressure: As the breach forms, the soil loses confining pressure. Internal instability of the soil increases the erosion rate, increasing $\mathrm{k}_{\mathrm{d}}$. Hanson et al [8] reported that compaction was one important factor governing $\mathrm{k}_{\mathrm{d}}$ variability. This would be a general case, encountered in most breaches, and would not be dependent on local soil properties. However, while loss of confining pressure explains temporally variable, apparent soil conditions, they trend in the opposite direction of the trend observed in the modeling results.

2. Local Soil Heterogeneity: The breach encounters different layers or pockets of material in heterogeneous embankments. The breach exploits the weakest material first (highest $\mathrm{k}_{\mathrm{d}}$ ). When the breach is small it is in contact with only that weak, erodible material, but as it grows it is governed by more average conditions. So soil erodibility drops with time. This process would be more site specific, dependent on the individual levee and failure mode, but trends in the right direction to explain model results.

3. Erodibility Non-linearity: Erodibility has been defined by some as non-linear [25]. The excess shear formulation assumes that erosion is non-linear with shear stress, but the erodibility coefficient is taken as the linear slope of that relationship. The cause of non-linearity may be the differing scale of erosive forces as flow velocity increases. Erosive forces are not acting on particles or small clumps of soil, but blocks or other massive 
elements. In addition as velocity increases, entrainment increases, the particle to particle interactions become more prevalent, and fluid density increases such that the slurry is not acting like pure water. The breach flow during the initial phase is highly turbulent and fast, exerting a much higher hydraulic shear stress. Prototype erosion may diverge too far from laboratory shear erosion used to measure $k_{d}$ and $t_{c}$ in the turbulent breach formation stage, requiring higher erodibility parameters. Once the breach cuts to its full depth and the breach flows slow, widening may be governed by parameters and processes more like the laboratory scale.

4. Compensation for Bias: Erodibility coefficients may compensate for model biases. All three models assume that widening rates are a ratio (between 0.3 and 0.5 ) of the incision rate. Therefore, the models use a much more detailed incision model than widening. The widening ratio selected might systematically under predict the widening rate or the process might be sufficiently dissimilar that a linear ratio might not capture widening.

\subsection{Future Work}

Application of these models to an overtopping breach case would further explain their applicability for levees and allow testing of the overtopping headcut and surface protection erosion routines.

Applying these models to levee breach applications sometimes requires tightly coupled feedbacks between breach formation and tailwater hydraulics. Therefore HEC is planning to include one of them in HEC-RAS to compute breach formation-hydraulic feedbacks on a time step scale.

Further research into the factors affecting headcut formation would aid users in model selection.

Defining common expected soil properties would help users select appropriate model parameters. Consider a range of parameters keyed to a soil type or compositional size fractions ( $\%$ sand, silt, clay) with index properties and ability to adjust the most sensitive ones. This would simplify parameter selection and focus the user on the most important ones.

\section{Conclusion}

1. Physically based dam breach models can be applied to levees with consideration for the unique hydraulic conditions. The models perform best during initial, rapid breach widening, but may start to diverge when tailwater impacts breach flow.

2. Headwater and tailwater assumptions can drive the breach progression toward more incorrect solutions. Coupling the breach model with a hydraulic model to gain the benefit of proper headwater and tailwater would allow the user to test breach sensitivities under more realistic hydraulic conditions, solving many of the difficulties seen in this study.
3. Soil properties seem to be the largest source of uncertainty in the modeling, assuming reasonable assumptions can be made for headwater and tailwater. The user should collect as much soil data as possible for the levee under study, determine the range of possible values, and test their sensitivities in the breach model.

\section{Acknowledgements}

This paper would not be possible without the generous support from Bryant Robbins, Alejandro Sanchez, Gary Brunner, Jason Needham, Scott Shewbridge, Don Moses, Lowell Blankers, Jeff McClenathan, and Keith Kelson of USACE. Many thanks also to the model developers who assisted in model preparation and setup: Darryl Temple, Karl Visser, Mark Morris, Mohamed Hassan, and Weiming $\mathrm{Wu}$.

Funding was provided by the USACE Risk Management Center, Levee Breach Parameter Study and the ERDC Coastal and Hydraulics Lab.

The views expressed in this paper are those of the authors and do not necessarily reflect the policy or position of the US Army Corps of Engineers.

\section{References}

[1] USACE, Institute for Water Resources (2010). Exploration of Tolerable Risk Guidelines for the USACE Levee Safety Program. IWR Workshop Proceedings, Washington, DC.

[2] Needham J T, Seda-Sanabria Y, Bowles D S (2010). Consequence Estimation for Critical Infrastructure Risk Management. Proceedings of US Society on Dams Conference, Sacramento, California, USA.

[3] US Bureau of Reclamation and US Army Corps of Engineers (2015). Best Practices in Dam and Levee Safety Risk Analysis. Accessed at www.usbr.gov/ssle/damsafety/risk/methodology.html

[4] Morris M W, Hassan M A A M, Wahl T L, Tejral R D, Hanson G J, Temple D M (2012). Evaluation and Development of Physically-Based Embankment Breach Models. Report of the Dam Safety Interest Group for CEATI International.

[5] ASCE/EWRI Task Committee on Dam/Levee Breaching, Weiming Wu, Chairman (2011). Earthen Embankment Breaching. J of Hydraulic Engineering, 137, 1549-1564.

[6] Kakinuma T and Yasuyuki S (2014). Large-Scale Experiment and Numerical Modeling of a Riverine Levee Breach. J of Hydraulic Engineering, accessed online, ISSN: 0733-9429/04014039(9).

[7] Brunner, G W (2015). HEC-RAS River Analysis System Hydraulic Reference Manual. US Army Corps of Engineers Software Documentation for HEC-RAS 5.0. CPD 69.

[8] Hanson G J, Temple D M, Morris M, Hassan M, Cook K (2005). Simplified Breach Analysis Model 
for Homogeneous Embankments: Part II, Parameter Inputs and Variable Scale Model Comparisons. Proceedings of US Society on Dams Conference, Technologies to Enhance Dam Safety and the Environment, Salt Lake City, Utah, USA, 163-174.

[9] Wu W (2015). Introduction to DL Breach - A Simplified Physically-Based Dam/Levee Breach Model (Draft). Clarkson University, 2015.7

[10] Wu W (2013). Simplified Physically Based Model of Earthen Embankment Breaching. J of Hydraulic Engineering, 139(8), 837-851.

[11] Visser P J (1998) Breach Growth in Sand-Dikes. Dissertation for Doctorate at Technical University of Delft, the Netherlands.

[12]Zhu Y (2006) Breach Growth in Clay-Dikes. Dissertation for Doctorate at Technical University of Delft, the Netherlands.

[13] Hassan M A A M and Morris M W (2008). HR BREACH Help File, HR Wallingford, v1.1.

[14] Hanson G J, Temple D M, Hunt S L, Tejral R D (2011). Development and Characterization of Soil Material Parameters for Embankment Breach. Applied Engineering in Agriculture, 27(4), 587-595.

[15] USDA-ARS (2011). WinDAM B Dam Overtopping Model, Software Documentation for WinDAM B, V1.0.0.

[16] Visser K, Tejral R D, and Neilsen M L (2015). WinDAM C Earthen Embankment Internal Erosion Analysis Software. Proceedings of the $3^{\text {rd }}$ Interagency Conference on Sedimentation and Hydrologic Modeling, Reno, Nevada, USA.

[17] Wu W (2016). Personal Communication with Author.

[18] Wahl T L (2004). Uncertainty of Predictions of Embankment Dam Breach Parameters. J of Hydraulic Engineering, 130(5), 389-397.

[19] Long R (2016). Personal Communication with Author. Former RD 1660 General Manager, Ronald Long.

[20] USACE, Sacramento District (1997). Collection of Emergency Situation Reports and Emergency Repair Design Documents. Unpublished.

[21] Flood Emergency Action Team (1997). Final Report. Governor's Task Force on 1997 Flooding in California.

[22] Moses, D (2015). Personal Communication with Author. Geotechnical Investigator of Hamburg Levee Failure, Omaha District, USACE.

[23] Blankers, L (2015). Personal Communication with Author. Hydraulic Investigator of Hamburg Levee Failure, Omaha District, USACE.

[24] Hanson G J and Simon A (2001). Erodibility of Cohesive Streambeds in the Loess Area of the Midwestern USA. Hydrological Processes, 15, 2338.

[25] Wu W and Perera C (2015). Erosion of Mixed Cohesive and Non-Cohesive Sediments. Final Report on laboratory experiments submitted to US Army Engineer Research and Development Center. 